\title{
Efficacy of tocilizumab for refractory Takayasu arteritis: a retrospective study and literature review
}

\author{
Haiyan $\mathrm{Li}^{1} \cdot$ Zongwen Shuai $^{1}$
}

Received: 13 July 2021 / Accepted: 29 October 2021 / Published online: 8 November 2021

(c) The Author(s) 2021

\begin{abstract}
To evaluate the efficacy and safety of tocilizumab (TCZ) in the treatment of refractory Takayasu arteritis (TAK). Eleven refractory TAK patients treated with TCZ at the First Affiliated Hospital of Anhui Medical University between 2017 July and 2020 December were respectively analyzed. We also respectively analyzed the studies on TCZ efficacy in patients with TAK, from PubMed/MEDLINE, Elsevier Science Direct between January 2010 and April 2021. The median age of 11 patients was 34(19-46) years. After 3 months of TCZ, a significant drop was found in median NIH (3[2-5] at baseline vs 1[0-2] after 6 months; $p<0.05)$, ITAS-2010 score (8.5[6-11] vs 6[1-10]; $p<0.05)$. One (9\%) patient experienced relapse during TCZ treatment. After withdrawal of TCZ, one patient (9\%) underwent relapse and nine patients (81\%) were spared of GC use. In literature review, a total of 211 patients (mean age 35 years) were analyzed, including 80 (38\%) Chinese and 169 females (80\%). Among the 211 patients, (154 patients) 73\% achieved remission after the last infusion of TCZ; TAK relapsed in 6\% of patients during TCZ treatment and $5 \%$ of the TCZ patients after the withdrawal of TCZ. A total of 95 types of adverse events were observed in the literature. Infection was the most common adverse effect, occurring in 50\% of patients. TCZ could serve as an efficacious and safe agent for refractory TAK.
\end{abstract}

Keywords Takayasu arteritis $\cdot$ Tocilzumab $\cdot$ Interleukin- $6 \cdot$ C-reactive protein $\cdot$ Erythrocyte sedimentation rate

\section{Introduction}

Takayasu arteritis (TAK) is a major large vessel vasculitis involving the aorta, its major branches and the pulmonary arteries [1]. TAK is more prevalent in Asia and the Middle East than in other regions [2]. TAK predominantly affects the young women in their twenties or thirties [3]. Without early effective anti-inflammatory treatments, TAK patients may undergo relapse after continuous inflammation and vascular injury [4].

The pathogenesis of TAK remains unclear. Multiple studies have revealed the active roles of pro-inflammatory cytokines, including tumor necrosis factor $\alpha(\mathrm{TNF} \alpha)$ and interleukin-6 (IL-6). IL-6 level increases in the serum, so does its expression in the aorta [5, 6]. In addition, IL-6 can mark the activity of various diseases [7]. Therefore, baseline

Zongwen Shuai

shuaizongwen@ahmu.edu.cn

1 Department of Rheumatology and Immunology, The First Affiliated Hospital of Anhui Medical University, Hefei 230022, China
IL-6 level has been suggested to predict TAK relapse during a long-term follow-up [8]. Blockade of IL-6 signaling may counter TAK, which has been testified in experimental or clinical studies [9].

Glucocorticoids (GCs) can induce remission in almost $60 \%$ of TAK patients [10]. However, their long-term use results in various side effects, and brings with a high rate of relapse, even the dosage is tapered off gradually [11]. To overcome these events, traditional immunosuppressive agents are recommended [12]. However, those patients with a high disease activity may not react sufficiently.

Tocilizumab (TCZ), a humanized monoclonal antibody targeting the IL-6 receptor subunit alpha (IL-6Ra), has demonstrated a significant efficacy against rheumatoid arthritis. A number of observational studies and randomized control trials (RCTs) have reported that TCZ renders clinical improvement and curbs TAK progression [13]. More importantly, TCZ could alter the mural thickness of arteries affected, thereby facilitating the reduction of steroid dose $[14,15]$. 
We report herein a retrospective study and a literature review on the efficacy and tolerance of TCZ in Chinese patients.

\section{Methods}

\section{Patients and methods}

\section{Patients}

This was a retrospective single-center study based on patients aged 16 or more at the moment of informed consent and recruited from the First Affiliated Hospital of Anhui Medical University between July 2017 and December 2020. The diagnosis was established according to the Indian Takayasu clinical activity score (ITAS2010). The data of patients' clinical manifestations, laboratory indexes, imaging features and treatment outcomes at TCZ initiation, 3, 6 and 12 months were recorded. The dosage of GCs was $8 \mathrm{mg} / \mathrm{kg}$ (once a month, intravenous infusion).

\section{Clinical efficacy assessment and definition}

The clinical efficacy was determined as favorable changes in symptoms and signs, GC dosage and imaging features after TCZ treatment. Remission was defined as lack of clinical manifestations of active disease and daily prednisone dosage less than $10 \mathrm{mg} /$ day with a $\mathrm{NIH}<2$. Relapse was defined as a condition, in which remission had been achieved, but disease turned active again, and treatment was needed.

\section{Search strategy}

From PubMed/MEDLINE, Elsevier Science Direct, we searched studies about TCZ in the treatment of TAK. All articles were limited to full text, English language, and publication date between January 2010 and April 2021. The keywords included TAK, TCZ, inerleukin-6/IL-6. Studies with patients aged $<16$ years and case reports with less than five subjects were excluded.

\section{Retrospective analysis}

All the data were collected from outpatient and inpatient medical records, including clinical manifestations, blood biochemical indexes and follow-up information was compared with our reports (2021), Abisror et al. [16], Goel et al. [17], Tombetti et al. [18], Canas et al. [19], Mekinian et al. [20], Loricera et al. [21], Zhou et al. [15], Mekinian et al. [12], Nakaoka et al. [13], Kilic et al. [22], Kong et al. [23], Pan et al. [24], Wu et al. [25] research group.

\section{Statistical analysis}

Continuous variables were presented as medians with ranges, and qualitative variables as frequencies with percentages. Fisher's exact test was carried out to compare qualitative variables. We used independent samples $t$ test to analyze continuous variables with normal distribution and the Mann-Whitney or Wilcoxon test to compare continuous variables with non-normal distribution. As appropriate. $p<0.05$ was considered as statistically significant.

\section{Results}

\section{Patient characteristics}

A total of patients (one male, ten females) with TAK were included in the study. The mean age at disease onset was 34 years (ranges 19-46 years), similar to that reported in other TAK patients. The average duration of TAK before TCZ treatment was 32.3 months. Three patients discontinued TCZ after first infusion. Two patients refused TCZ due to high cost and one for neutropenia and pneumonia. The main parameters about disease activity are described in Table 1. The levels of acute inflammatory markers showed a remarkable decrease. After TCZ therapy for 6 months, C-reactive protein (CRP) decreased from $34.1 \mathrm{mg} / \mathrm{L}$ (13.3-55.1) to $0.6 \mathrm{mg} / \mathrm{L}(0.3-0.9)$, erythrocyte sedimentation rate (ESR) from $41.6 \mathrm{~mm} / \mathrm{h}(29-49)$ to $10.5 \mathrm{~mm} / 1 \mathrm{~h}$ (4.3-15.3). NIH scores declined significantly from 3 (2-5) to $1(0-2)(p<0.001)$, ITAS2010 baseline from $7(6-9)$ to $3(1-5)(p<0.001)$. After a 6-month TCZ treatment, the dosage of GCs was reduced from $35.5 \mathrm{mg}(30-50)$ to $3.1 \mathrm{mg}$ (0-6.9) (Fig. 1). Eight patients (72.7\%) achieved remission after six infusions of TCZ. Six patients $(54.5 \%)$ developed vascular bruits. Four patients (36.4\%) showed pulse weakness. Two patients showed a change of over $10 \mathrm{mmHg}$ in blood pressure. Among the vascular manifestations in different studies, vascular bruits accounted for the biggest proportions $(54.5 \%, 100 \%, 100 \% .92 .6 \%$, respectively).

\section{Outcomes between post-treatment 6 months and 12 months}

Among the 8 patients, 3 patients (27\%) continued to receive a total of 12 infusions. The other five patients (45\%) received 6 months of TCZ and then GCs without TCZ. During the 12-month follow-up, seven patients $(64 \%)$ were treated with only steroids, and one patient (9\%) was not exposed to any other treatment (Table 1). All eight patients displayed no relapse. 
Table 1 Patients' characteristics at initiation of TCZ and during follow-up
Fig. 1 Daily prednisone dosage during a 12-month follow-up

\begin{tabular}{lllll}
\hline & At initiation of TCZ & At 3 months & At 6 months & At 12 months \\
\hline Patients treated with TCZ $(\%(n))$ & $11(100)$ & $8(72.7)$ & $8(72.7)$ & $3(27.3)$ \\
NIH score & 3 & 2 & $1^{*}$ & 1 \\
ITAS 2010 & 7 & 3 & $3^{*}$ & 2 \\
Remission $(\%)$ & 0 & $5(45.5)$ & $8(72.7)$ & $3(27.3)$ \\
CRP & 34.1 & $0.6^{*}$ & $0.6^{*}$ & $1.6^{*}$ \\
ESR & 41.6 & $5.5^{*}$ & $8.0^{*}$ & $10.5^{*}$ \\
Prednisone (mg/day) & 35.5 & $4.2^{*}$ & $3.1^{*}$ & $3.1^{*}$ \\
Immunosuppressive drugs & AZP $(n=2) ;$ CTX $(n=3) ;$ & 0 & 0 & 0 \\
& MTX $(n=2) ;$ MMF $(n=2) ;$ & & \\
WBC $\left(10^{9} / \mathrm{L}\right)$ & TK506 $(n=1)$ & & & \\
NE $\left(10^{9} / \mathrm{L}\right)$ & 8.4 & 10.7 & 9.74 & 8.2 \\
LY $\left(10^{9} / \mathrm{L}\right)$ & 5.1 & 5.7 & 6.0 & 5.4 \\
PLT $\left(10^{12} / \mathrm{L}\right)$ & 2.3 & 3.3 & 3.0 & 2.2 \\
NLR & 268.2 & 268.0 & 261.0 & 237.5 \\
PLR & 2.6 & 1.7 & 2.1 & 3.5 \\
RBC $\left(10^{12} / \mathrm{L}\right)$ & 139.7 & 80.9 & 88.7 & 106.8 \\
Hb $(\mathrm{g} / \mathrm{L})$ & 4.3 & 4.3 & 4.4 & 4.4 \\
ALT $(\mathrm{U} / \mathrm{L})$ & 115 & 122 & 121 & 139 \\
Cr $(\mu \mathrm{mol} / \mathrm{L})$ & 19.1 & 16.5 & 19.3 & 18 \\
Glu $(\mathrm{mmol} / \mathrm{L})$ & 74.6 & 55 & 55.3 & 58.8 \\
\hline & 4.6 & 4.5 & 4.7 & 5.1 \\
\hline
\end{tabular}

$A L T$ alanine aminotransferase; $C r$ creatinine; $C R P$ C-reactive protein; $E S R$ erythrocyte sedimentation rate; Glu glucose; $H b$ hemoglobin; $L Y$ lymphocyte; $N E$, neutrophil; $N L R$, neutrophil-to-lymphocyte ratio; $P L T$ platelets; $P L R$ platelet-to-lymphocyte ratio; $R B C$ red blood cell; $W B C$ white blood cell

$* p<0.05$

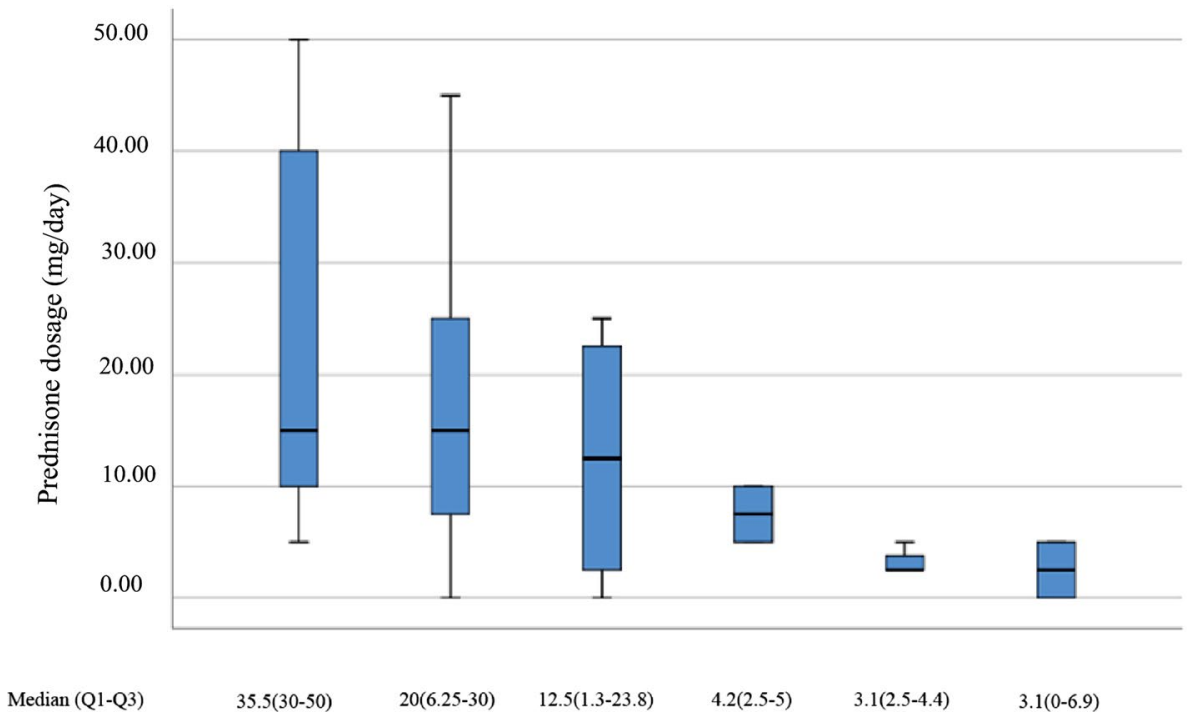

\section{Literature review}

A total of 211 patients (mean age 35 years) were reviewed, including 80 (38\%) Chinese and 169 females (80\%). Their demographic characteristics and clinical manifestations are concluded in Table 2. For Chinese patients, the median duration from disease onset to TCZ treatment was 12 (6-12) months, shorter than that reported in other populations (mean 16 months, ranges 11-24 months). Overall, type $\mathrm{V}$ vasculitis $(45 / 110,40.9 \%)$ was the most common type among all populations, followed by Type. In China, type I topped others $(25 / 71,35.2 \%)$, followed by type V 


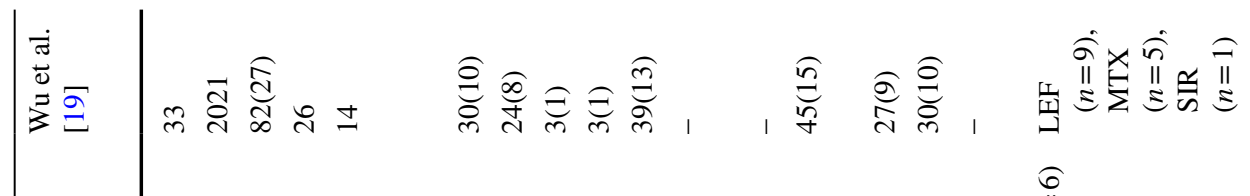

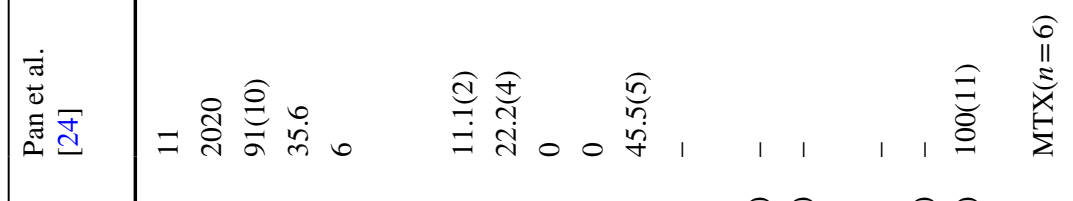

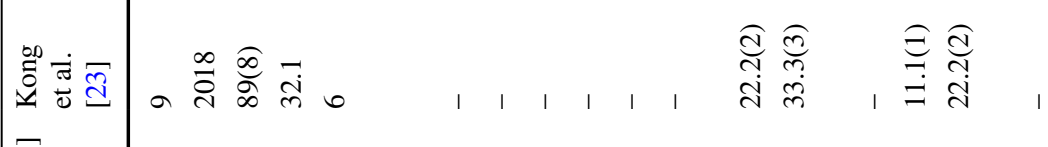

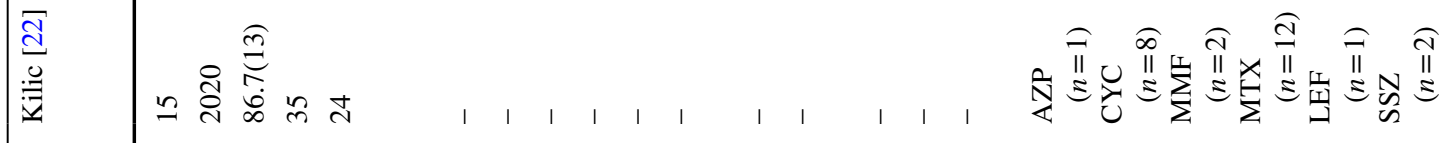

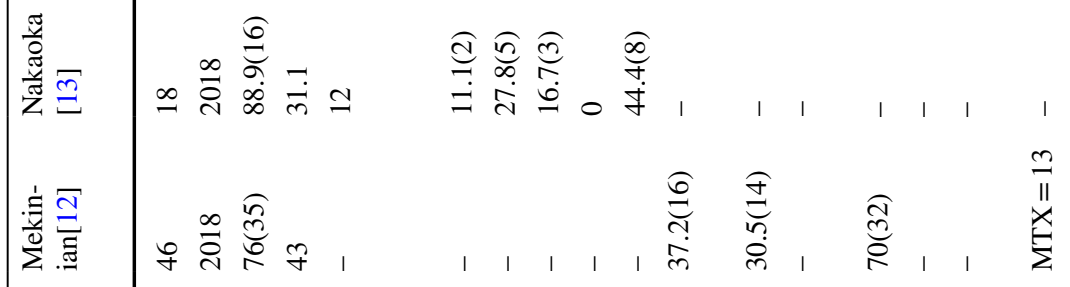

$$
\begin{aligned}
& \stackrel{0}{3} \\
& \text { 氖 }
\end{aligned}
$$

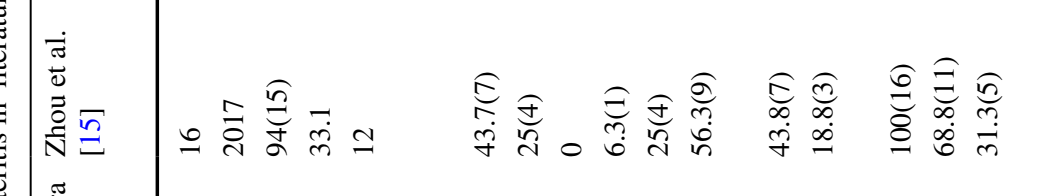

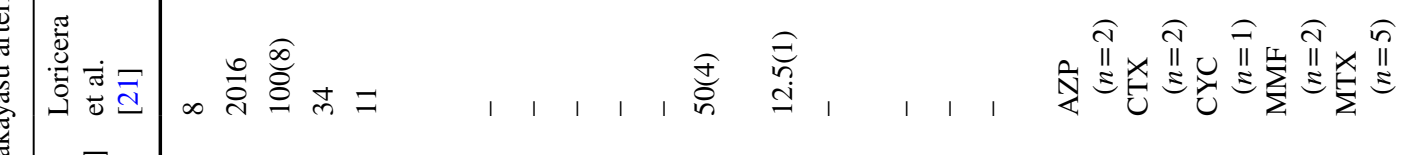

$$
\begin{aligned}
& \text { 递 } \\
& \text { 苞 }
\end{aligned}
$$

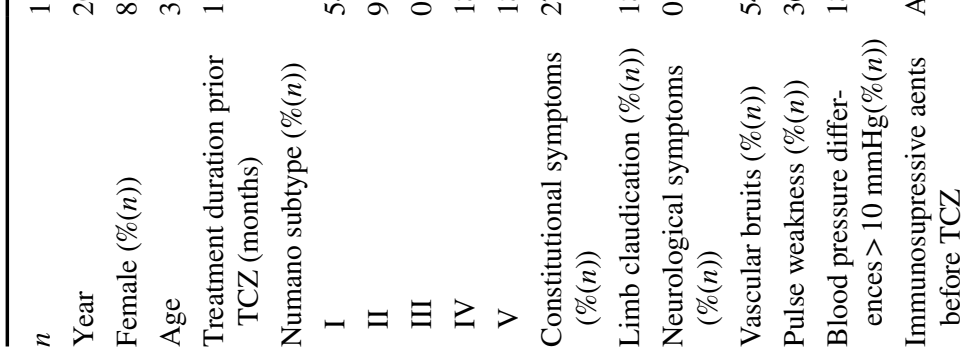$$
\text { 莺 }
$$$$
3
$$$$
\text { 苟 }
$$

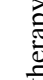

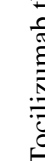




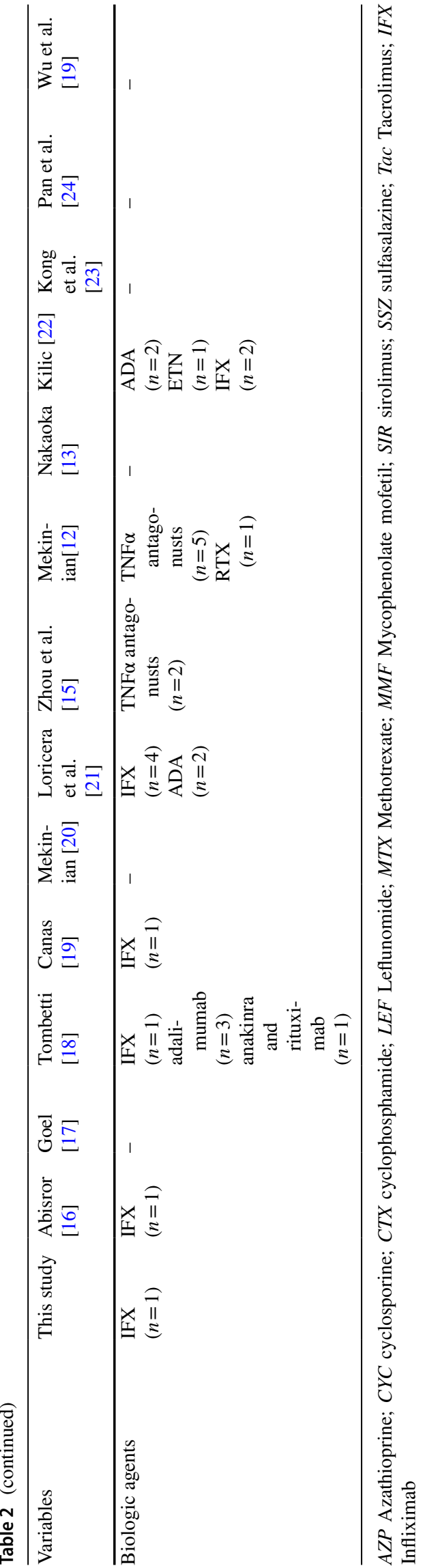

(24/71, 33.1\%) based on the 1996 Numano classification. However, in other populations, type $\mathrm{V}$ accounted for the highest proportion $(21 / 39,54 \%)$, followed by type II ( $8 / 39$, $20.5 \%$ ). Vascular bruits were found in $67(36.2 \%)$, constitutional symptoms in $12(6.5 \%)$, limb claudication in 27 (14.6\%), neurological symptoms in $23(12.4 \%)$, pulse weakness in 32 (17.3\%), abnormal blood pressure in 24 (13\%) patients. In China, vascular bruits were found in $31(38.8 \%)$, constitutional symptoms in 12 (15\%), limb claudication in $11(13.8 \%)$, neurological symptoms in 21 (26.3\%), and pulse weakness in 45 (39\%) patients. Before the use of TCZ, more than half of the whole populations had received traditional immunosuppressive agents. MTX (47.4\%) was the most frequently used. Prior to TCZ therapy, anti-TNF $\alpha$ was the most common, found in $89 \%$ $(22 / 25)$ of all agents.

The already-reported responses to TCZ are summarized in Table 3. Among the 211 patients reviewed, 154 (73\%) patients achieved clinical remission after TCZ treatment. Clinical remission was achieved in $82.5 \%$ of Chinese patients, and $67.2 \%$ in overseas patients, though assessment criteria of disease activity were different. The median TCZ duration was 7.9 (6-18) months. Among the 211 patients, (154 patients) $73 \%$ achieved remission after the last infusion of TCZ; TAK relapsed in $6 \%$ of patients during TCZ treatment and 5\% of the TCZ patients after the withdrawal of TCZ. In China, only one (1.2\%) patient experienced relapse during TCZ treatment, significantly fewer than those overseas $(n=4, p=0.026)$. After withdrawal of TCZ, seven $(8.8 \%)$ patients showed a relapse. All the studies in China revealed that the use of TCZ led to a significant reduction in the dosage of GCs. Most importantly, the percentage of TAK patients with relapse during TCZ treatment in our study was significantly lower than that in overseas studies.

The laboratory parameters are summarized in Table 3. The levels of acute phase inflammation markers, including CRP and ESR, varied a lot among all patients. Additionally, after TCZ treatment, the counts of white blood cells (WBs) and neutrophils (NEs) decreased, but the counts of lymphocytes (LYs), red blood cell (RBCs), platelets (PLTs) and hemoglobin increased, as compared with those before TCZ treatment.

\section{Safety}

One patient (9.1\%) withdrew TCZ because of leukopenia and pulmonary infection in our study. A total of 95 types of adverse events were reported in the literature. Infection was the most common adverse effect, observed in $50 \%$ of patients. Liver enzyme abnormality was the least common adverse effect. Newly diagnosed or deteriorated neck pain was the second most common adverse event in 
Chinese patients (20\%). Other adverse effects included skin rash, liver enzyme abnormality, gastro-intestinal disorders, and neoplasms. No serious adverse effects and death were observed. Figure 2 shows the adverse effects in other studies and ours.

\section{Discussion}

Our study clarified the potential efficacy of TCZ in Chinese patients with refractory TAK in the active phase. During the 6-month follow-up, TCZ significantly decreased the ESR, CRP, and NIH scores as well as ITAS 2010 in patients with TAK. The present study is possibly the first to elegantly describe the characteristic of global TAK patients and the efficiency of TCZ using the diagnostic standard in 1990 American College of Rheumatology (ACR). Consistent with previous overseas studies, the present study held that TAK mainly attacks the young female patients [26]. Types I and V showed up in more than 50\% of Chinese TAK patients. In other countries, types II and V were the most common. In either China or other countries, the vascular bruits are the most common vascular sign.

In our study, TCZ was used as an optional therapy for those patients who failed to adequately respond to GCs and immunosuppressive agents (100\%) or anti-TNF agents (9.1\%). Patients with TAK took the GCs combined with disease-modifying rheumatic drugs (DMARDS) as the first-line strategy. CTX and MTX were the most common DMARDs (in $27.8 \%$ and $24.1 \%$, respectively) to be combined with GCs. However, Ohigashi has reported that more than $50 \%$ of TAK patients treated with GC monotherapy suffered from disease flare during GC dosage tapering [27]. Considering the high rate of relapse after GC therapy, immunosuppressive agents and/or biological agents are supplemented to provide more benefits. In our analysis, 45 TAK patients lacking clinical response to GCs and anti-TNF agents benefited from TCZ therapy.

The management of TAK has not been standardized. One study has shown that TCZ and anti-TNF $\alpha$ agents triggered similar partial and complete responses at posttreatment 3, 6 and 12 months [12]. Our study demonstrated that TCZ was usually prescribed as an optional drug after traditional immunosuppressive or anti-TNF $\alpha$ agents failed to produce desirable effects. Anti-TNF $\alpha$ agents are used as the first choice, but cannot induce remission in more than $10 \%$ of patients. However, a 6-month treatment of TCZ realized clinical remission in our analysis. Tombetti has reported the similar results in seven patients with refractory TAK from a single center [18]. Moreover, Shuai et al. found that TCZ, compared to anti-TNF $\alpha$ agents, achieved a higher remission rate and a lower relapse rate $(70 \%$ vs $65 \%, 17 \%$ vs $20 \%$, respectively) [28].
The efficacy of TCZ in treating newly diagnosed TAK patients or refractory TAK patients has been explored in European randomized trials and prospective trials [26, 29]. As shown in our review, all the studies reported significant improvement in disease activity (Kerr score or NIH or ITAS2010) as well as the laboratory parameters (mainly CRP and ESR). In TAK management guidelines, inflammatory markers are recommended as tools to monitor disease activity [30]. In the presence of TCZ, the dosage of GCs can be reduced [31]. TCZ can also increase the event-free survival rate [12]. In the present study, one patient maintained remission, although GCs dosage was reduced after a 6-month treatment of TCZ. Lo Gullo et al. also reported that a TAK patients resistant to traditional immunosuppressive drugs achieved a steroid-sparing condition through subcutaneous administration of TCZ [32], suggesting that TCZ can reduce the dosage of traditional immunosuppressive drugs, while maintain the remission in TAK patients. Our study also supported that after withdrawal of TCZ; the disease activity could be well controlled [14]. The only prospective study of TAK reported a high rate of remission of $85 \%$ [26]. In contrast, the remission rate $(73 \%)$ in our study was significantly lower, probably because three patients discontinued TCZ use due to its high cost. TCZ induced complete clinical remission in $86 \%$ of Chinese patients, a rate close to that reported in a multicenter retrospective study [12]. In a previous study, the remission rate in DMARDs-treated patients was lower than that in naïve-treated patients, but their relapse rates were similar. In the present study, the relapse rate during TCZ treatment was much lower than that reported in the prospective study.

IL-6 is actively involved in the pathology of anemia of patients with TAK [15]. Zhang et al. reported that anemia was more likely to occur in young or female TAK patients with high disease activity [33]. The present study also supported that the level of hemoglobin increases with the reduction of acute inflammatory markers in TAK patients under remission.

Several studies of rheumatic disease revealed the close relationship of disease activity with platelet-to-lymphocyte ratio (PLR) as well as neutrophil-to-lymphocyte ratio (NLR) [34-36]. However, scant literature has analyzed the link between PLR/NLR and TCZ efficacy. This link was illustrated in the present study. Pan et al. suggested that a higher NLR indicated a higher disease activity in patients with TAK [35]. In the literature analysis, TAK patients showed decreased counts of leucocytes, NE and PLT, and increased counts of lymphocytes. NLR and PLR declined after the patients achieved remission, though without obvious discrepancies between Chinese and other populations. The pathological mechanism of TAK may involve the 


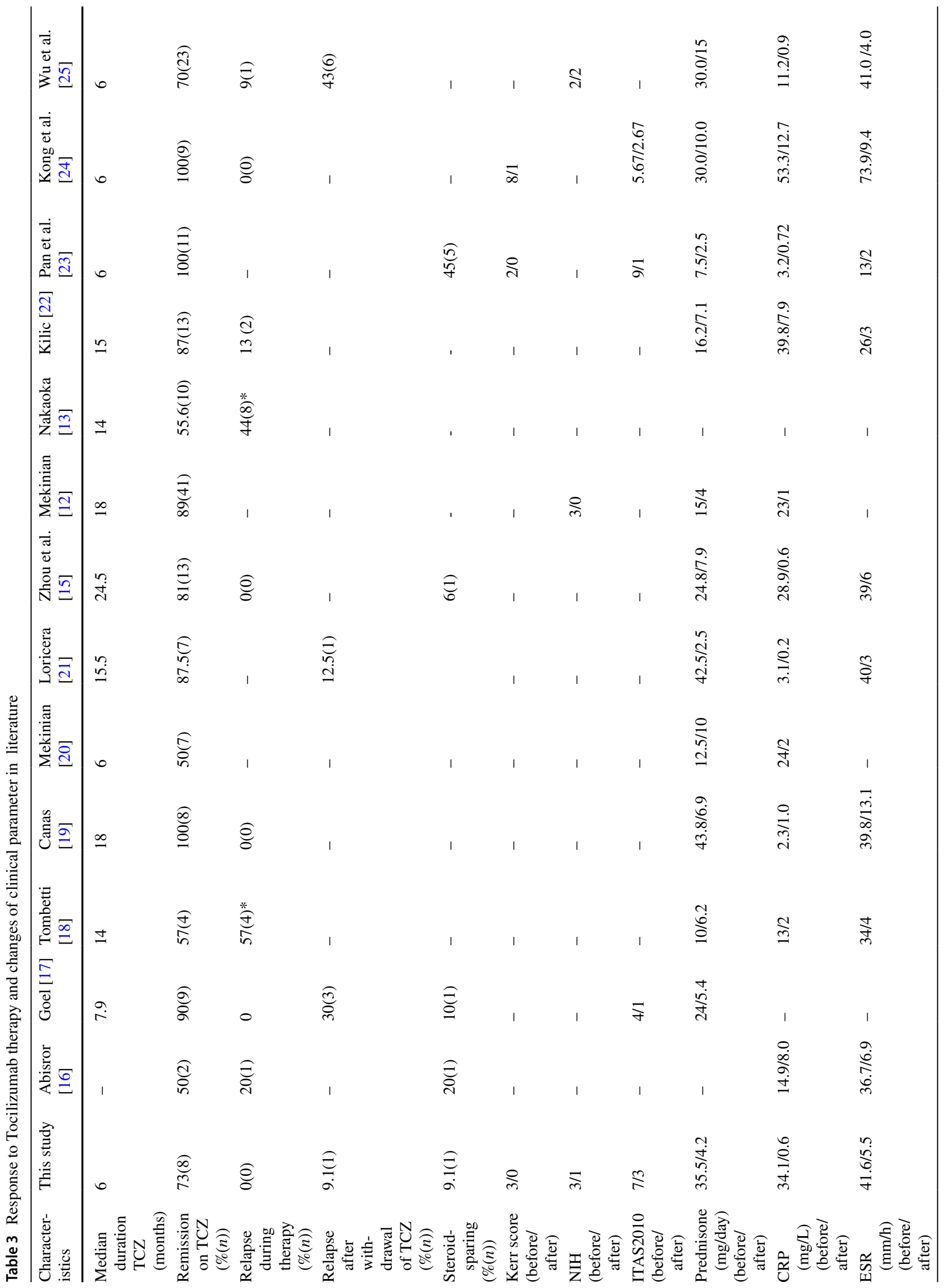


Heart and Vessels (2022) 37:884-894

891

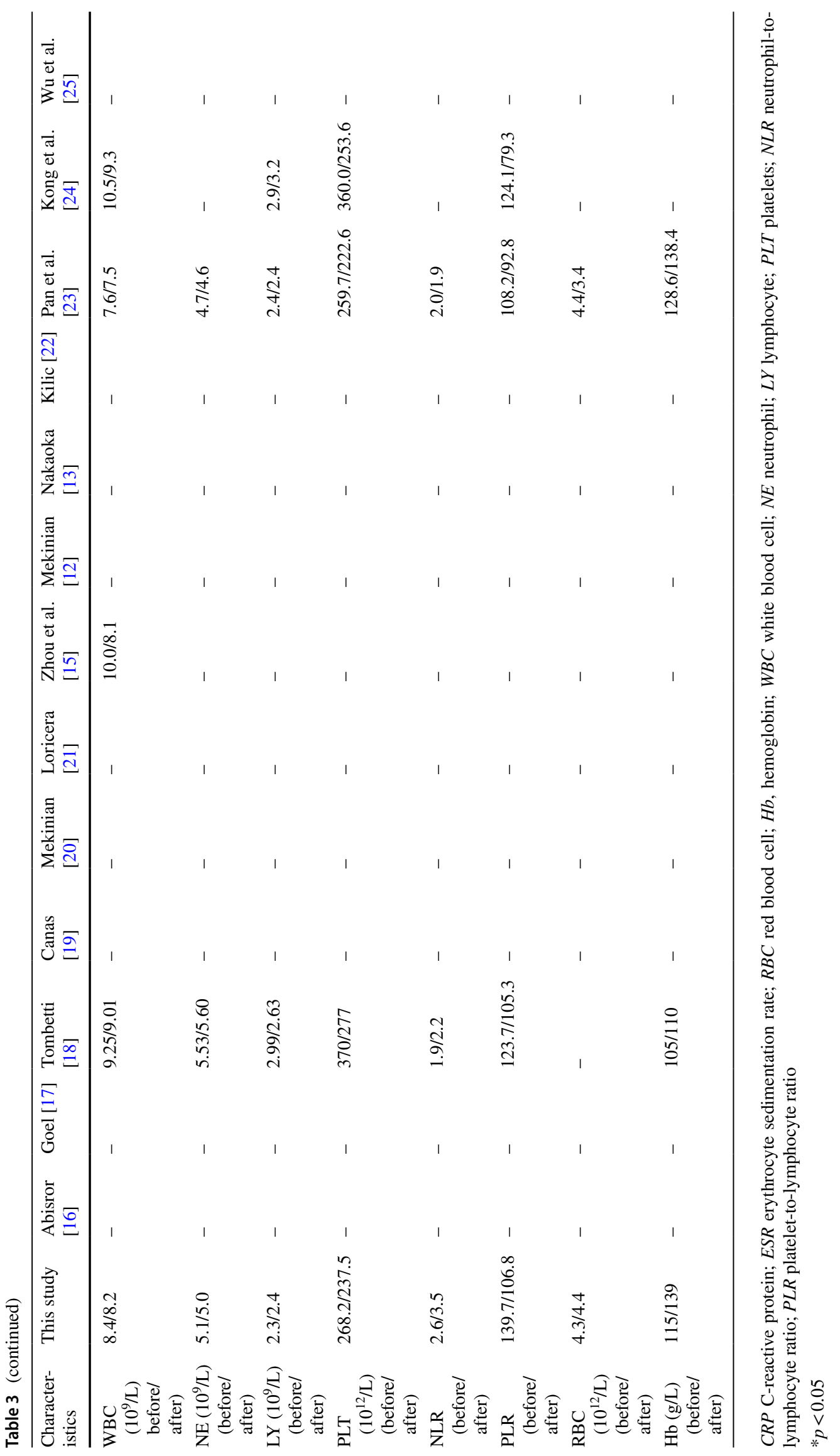

Springer 

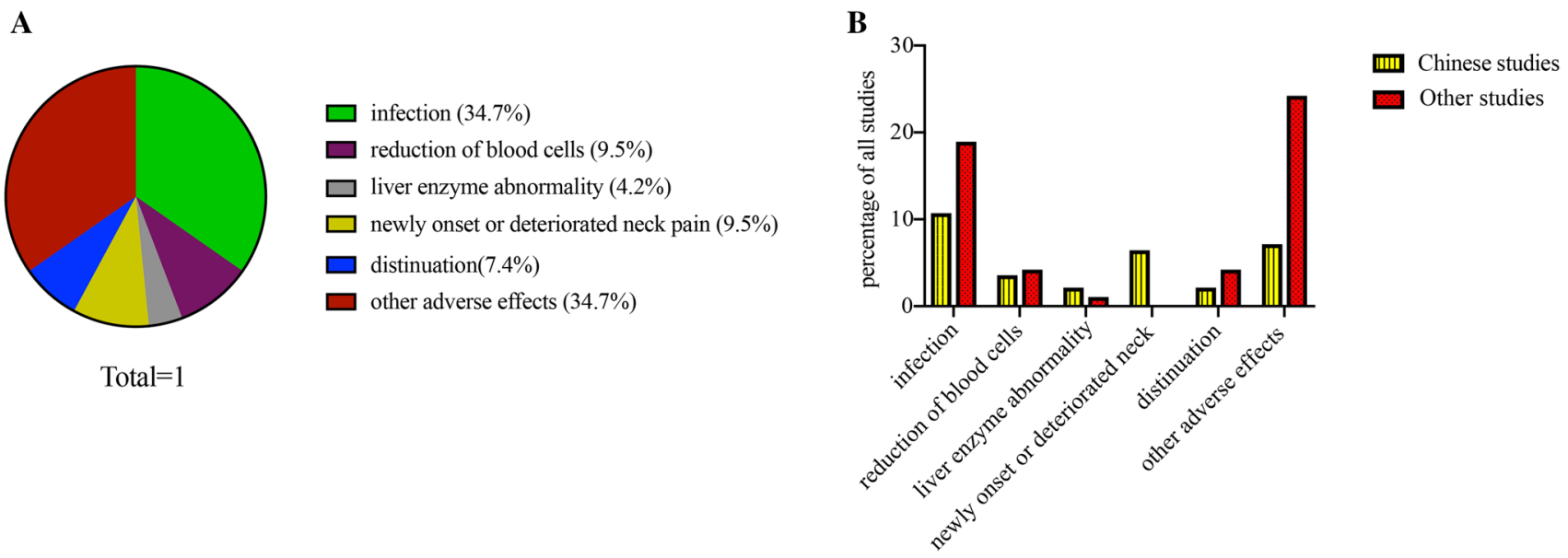

Fig. 2 Adverse events reported in the literature; types and proportions of infections in the literature. A Proportions of adverse events in the literature. B Types and proportions of infections in the literature

recruitment and infiltration of neutrophils in the aorta following arterial inflammation [37].

In our literature, $11(5 \%)$ patients received 18F-FDG PET/CT imaging to assess the disease activity of TAK. However, in China, 18F-FDG-PET was not extensively recommended to TAK patients because of high fees of 18F-FDG-PET. Recent studies recommended the 18F-FDGPET for monitoring the disease activity of TAK including assessment of the recurrence of TAK, since 18F-FDG-PET showed the simultaneous changes of inflammation in arterial walls and clinical course under the therapy of TCZ $[38,39]$. In summary, FDG-PET is a promising checking method to aid the clinical evaluation of disease activity.

The safety of TCZ has been validated in various autoimmune diseases [40-42]. In our study, neutropenia and severe pneumonia were observed in one patient $(9.1 \%)$ and this patient discontinued the use of TCZ because of adverse effects. In our study, adverse events were found in 32.5\% of Chinese TAK patients, with severe infections accounting for $16 \%$. These infections may arise from leukopenia and neutropenia. Additionally, high-dose or continuous GCs treatment may increase the risk of recurrent infections by bacteria or fungus, such as invasive Aspergillosis [43]. In our study, only one patient suffered from pulmonary bacterial infection originating from neutropenia. This condition has been revealed in other studies [43-45].

Another adverse effect is severe neck pain, which has also been reported in previous studies [15]. Zhou et al. observed that patients with new TAK onset or deteriorated neck pain had higher rates of constitutional symptoms and required higher GC dosage [15]. A significantly lower Hb concentration was also detected in such patients than in those without neck pain. Infections are more common in Chinese patients, but abnormal liver enzymes, new TAK onset or deteriorated neck pain appeared more frequently in other populations. No death was observed in our study.

This study has several limitations. First, the patients were only recruited from a single center. Hence, advanced studies are needed to verify the benefits of TCZ in contrast to traditional DMARDs.

\section{Conclusion}

TCZ demonstrated obvious efficacy and safety in naïvetreated patients and patients with refractory TAK. TCZ could also induce a long period of remission. However, large-scale open-label and randomized trials are required to assess its long-term efficacy and safety and figure out an optimal scheduling.

Acknowledgements We would like to thank the members of the Department of Rheumatology and Immunology in the First Affiliated Hospital of Anhui Medical University.

Authors' contributions Study design: HL and ZS. Collection and interpretation of data: HL. Manuscript writing: HL and ZS. Funding provider: ZS. All authors have read and approved the final manuscript.

Funding This study is supported by National Natural Science Foundation of China (Number: 8187061400).

\section{Declarations}

Conflict of interest All authors have no conflict of interests associated with this study.

Ethical approval All participants offered written informed consent. The study was conducted in accordance with the ethical principles of the Declaration of Helsinki and approved by The Committee on Medical Ethics of the First Affiliated Hospital of Anhui Medical University. 
Open Access This article is licensed under a Creative Commons Attribution 4.0 International License, which permits use, sharing, adaptation, distribution and reproduction in any medium or format, as long as you give appropriate credit to the original author(s) and the source, provide a link to the Creative Commons licence, and indicate if changes were made. The images or other third party material in this article are included in the article's Creative Commons licence, unless indicated otherwise in a credit line to the material. If material is not included in the article's Creative Commons licence and your intended use is not permitted by statutory regulation or exceeds the permitted use, you will need to obtain permission directly from the copyright holder. To view a copy of this licence, visit http://creativecommons.org/licenses/by/4.0/.

\section{References}

1. Tombetti E, Mason JC (2019) Takayasu arteritis: advanced understanding is leading to new horizons. Rheumatology (Oxford) 58(2):206-219

2. Onen F, Akkoc N (2017) Epidemiology of Takayasu arteritis. Presse Med 46(7-8 Pt 2):e197-e203

3. Mason JC (2010) Takayasu arteritis-advances in diagnosis and management. Nat Rev Rheumatol 6(7):406-415

4. Direskeneli H (2017) Clinical assessment in Takayasu's arteritis: major challenges and controversies. Clin Exp Rheumatol 35 Suppl 103(1):189-193

5. Berger CT, Rebholz-Chaves B, Recher M, Manigold T, Daikeler T (2019) Serial IL-6 measurements in patients with tocilizumabtreated large-vessel vasculitis detect infections and may predict early relapses. Ann Rheum Dis 78(7):1012-1014

6. Pulsatelli L, Boiardi L, Assirelli E, Pazzola G, Muratore F, Addimanda O, Dolzani P, Versari A, Casali M, Magnani L, Pignotti E, Pipitone N, Croci S, Meliconi R, Salvarani C (2017) Interleukin-6 and soluble interleukin-6 receptor are elevated in large-vessel vasculitis: a cross-sectional and longitudinal study. Clin Exp Rheumatol 35 Suppl 103(1):102-110

7. Tamura N, Maejima Y, Tezuka D, Takamura C, Yoshikawa S, Ashikaga T, Hirao K, Isobe M (2017) Profiles of serum cytokine levels in Takayasu arteritis patients: potential utility as biomarkers for monitoring disease activity. J Cardiol 70(3):278-285

8. Sun Y, Kong X, Cui X, Dai X, Ma L, Chen H, Chen R, Lv P, Lin J, Huang Q, Jin X, Jiang L (2020) The value of interleukin-6 in predicting disease relapse for Takayasu arteritis during 2-year follow-up. Clin Rheumatol 39(11):3417-3425

9. Kong X, Ma L, Ji Z, Dong Z, Zhang Z, Hou J, Zhang S, Ma L, Jiang L (2018) Pro-fibrotic effect of IL-6 via aortic adventitial fibroblasts indicates IL-6 as a treatment target in Takayasu arteritis. Clin Exp Rheumatol 36(1):62-72

10. Schmidt J, Kermani TA, Bacani AK, Crowson CS, Cooper LT, Matteson EL, Warrington KJ (2013) Diagnostic features, treatment, and outcomes of Takayasu arteritis in a US cohort of 126 patients. Mayo Clin Proc 88(8):822-830

11. Maksimowicz-McKinnon K, Clark TM, Hoffman GS (2007) Limitations of therapy and a guarded prognosis in an American cohort of Takayasu arteritis patients. Arthritis Rheum 56(3):1000-1009

12. Mekinian A, Resche-Rigon M, Comarmond C, Soriano A, Constans J, Alric L, Jego P, Busato F, Cabon M, Dhote R, Estibaliz L, Kone-Paut I, Landron C, Lavigne C, Lioger B, Michaud M, Ruivard M, Sacre K, Gottenberg JE, Gaches F, Goulenok T, Salvarani C, Cacoub P, Fain O, Saadoun D, French Takayasu Network (2018) Efficacy of tocilizumab in Takayasu arteritis: multicenter retrospective study of 46 patients. J Autoimmun 91:55-60

13. Nakaoka $Y$, Isobe $M$, Takei $S$, Tanaka $Y$, Ishii T, Yokota S, Nomura A, Yoshida S, Nishimoto N (2018) Efficacy and safety of tocilizumab in patients with refractory Takayasu arteritis: results from a randomised, double-blind, placebo-controlled, phase 3 trial in Japan (the TAKT study). Ann Rheum Dis 77(3):348-354

14. Saito S, Okuyama A, Okada Y, Shibata A, Sakai R, Kurasawa T, Kondo T, Takei H, Amano K (2019) Tocilizumab monotherapy for large vessel vasculitis: results of 104-week treatment of a prospective, single-centre, open study. Rheumatology (Oxford) 59(7):1617-1621

15. Zhou J, Chen Z, Li J, Yang Y, Zhao J, Chen H, Liu M, Sun F, Li M, Tian X, Zeng X (2017) The efficacy of tocilizumab for the treatment of Chinese Takayasu's arteritis. Clin Exp Rheumatol 35 Suppl 103(1):171-175

16. Abisror N, Mekinian A, Lavigne C, Vandenhende MA, Soussan M, Fain O, Club Rhumatismes et Inflammation, SNFMI (2013) Tocilizumab in refractory Takayasu arteritis: a case series and updated literature review. Autoimmun Rev 12(12):1143-1149

17. Goel R, Danda D, Kumar S, Joseph G (2013) Rapid control of disease activity by tocilizumab in 10 "difficult-to-treat" cases of Takayasu arteritis. Int J Rheum Dis 16(6):754-761

18. Tombetti E, Franchini S, Papa M, Sabbadini MG, Baldissera E (2013) Treatment of refractory Takayasu arteritis with tocilizumab: 7 Italian patients from a single referral center. J Rheumatol 40(12):2047-2051

19. Canas CA, Canas F, Izquierdo JH, Echeverri AF, Mejia M, Bonilla-Abadia F, Tobon GJ (2014) Efficacy and safety of antiinterleukin 6 receptor monoclonal antibody (tocilizumab) in Colombian patients with Takayasu arteritis. J Clin Rheumatol 20(3): $125-129$

20. Mekinian A, Comarmond C, Resche-Rigon M, Mirault T, Kahn JE, Lambert M, Sibilia J, Neel A, Cohen P, Hie M, Berthier S, Marie I, Lavigne C, Anne Vandenhende M, Muller G, Amoura Z, Devilliers H, Abad S, Hamidou M, Guillevin L, Dhote R, Godeau B, Messas E, Cacoub P, Fain O, Saadoun D (2015) Efficacy of biological-targeted treatments in Takayasu arteritis: multicenter, retrospective study of 49 patients. Circulation 132(18):1693-1700

21. Loricera J, Blanco R, Hernandez JL, Castaneda S, Humbria A, Ortego N, Bravo B, Freire M, Melchor S, Minguez M, Salvatierra J, Gonzalez-Vela C, Calvo-Rio V, Santos-Gomez M, Pina T, Gonzalez-Gay MA (2016) Tocilizumab in patients with Takayasu arteritis: a retrospective study and literature review. Clin Exp Rheumatol 34(3 Suppl 97):S44-53

22. Kilic L, Karadag O, Erden A, Sari A, Armagan B, Yardimci GK, Firat E, Kalyoncu U, Apras Bilgen S, Kiraz S, Ertenli I, Akdogan A (2020) Anti-interleukin-6 (tocilizumab) therapy in Takayasu's arteritis: a real life experience. Turk J Med Sci 50(1):31-36

23. Kong X, Zhang X, Lv P, Cui X, Ma L, Chen H, Liu H, Lin J, Jiang L (2018) Treatment of Takayasu arteritis with the IL-6R antibody tocilizumab vs. cyclophosphamide. Int J Cardiol 266:222-228

24. Pan L, Du J, Liu J, Liao H, Liu X, Guo X, Liang J, Han H, Yang L, Zhou Y (2020) Tocilizumab treatment effectively improves coronary artery involvement in patients with Takayasu arteritis. Clin Rheumatol 39(8):2369-2378

25. Wu S, Kong X, Cui X, Chen H, Ma L, Dai X, Ji Z, Yan Y, Huang Q, Sun Y, Jiang L (2021) Effectiveness and safety of tocilizumab in patients with refractory or severe Takayasu's arteritis: a prospective cohort study in a Chinese population. Jt Bone Spine 88(5): 105186

26. Mekinian A, Saadoun D, Vicaut E, Thietart S, Lioger B, Jego P, Bleibtreu A, Limal N, Connault J, Gottenberg JE, Lhorte P, Bertola JP, Delforge J, Ferreira-Maldent N, Perlat A, Talib Z, Vautier M, Savey L, Quiere I, Cacoub P, Fain O, Network FT (2020) Tocilizumab in treatment-naive patients with Takayasu arteritis: TOCITAKA French prospective multicenter open-labeled trial. Arthritis Res Ther 22(1):218

27. Ohigashi H, Tamura N, Ebana Y, Harigai M, Maejima Y, Ashikaga T, Isobe M (2017) Effects of immunosuppressive and biological 
agents on refractory Takayasu arteritis patients unresponsive to glucocorticoid treatment. J Cardiol 69(5):774-778

28. Shuai ZQ, Zhang CX, Shuai ZW, Ge SL (2021) Efficacy and safety of biological agents in the treatment of patients with Takayasu arteritis: a systematic review and meta-analysis. Eur Rev Med Pharmacol Sci 25(1):250-262

29. Lee YH, Song GG (2019) Efficacy and safety of tocilizumab in patients with refractory Takayasu arteritis. Ann Rheum Dis 78(1):e9

30. Maz M, Chung SA, Abril A, Langford CA, Gorelik M, Guyatt G, Archer AM, Conn DL, Full KA, Grayson PC, Ibarra MF, Imundo LF, Kim S, Merkel PA, Rhee RL, Seo P, Stone JH, Sule S, Sundel RP, Vitobaldi OI, Warner A, Byram K, Dua AB, Husainat N, James KE, Kalot MA, Lin YC, Springer JM, Turgunbaev M, Villa-Forte A, Turner AS, Mustafa RA (2021) 2021 American College of Rheumatology/Vasculitis Foundation guideline for the management of giant cell arteritis and Takayasu arteritis. Arthritis Rheumatol 73(8):1349-1365

31. Decker P, Olivier P, Risse J, Zuily S, Wahl D (2018) Tocilizumab and refractory Takayasu disease: four case reports and systematic review. Autoimmun Rev 17(4):353-360

32. Lo Gullo A, Mandraffino G, Aragona CO, Molica Colella A, Saitta A, Imbalzano E (2017) Subcutaneous administration of tocilizumab is effective in myointimal hyperplasia remodelling in refractory Takayasu arteritis. Reumatismo 69(4):184-188

33. Zhang Y, Zhang D, Qu Y, Fan P, Liu YX, Zhang HM, Song L, Ma WJ, Wu HY, Cai J, Luo F, Zhou XL, Zheng DY, Liu LS (2019) Anemia in patients with Takayasu arteritis: prevalence, clinical features, and treatment. J Geriatr Cardiol 16(9):689-694

34. Gasparyan AY, Ayvazyan L, Mukanova U, Yessirkepov M, Kitas GD (2019) The platelet-to-lymphocyte ratio as an inflammatory marker in rheumatic diseases. Ann Lab Med 39(4):345-357

35. Pan L, Du J, Li T, Liao H (2017) Platelet-to-lymphocyte ratio and neutrophil-to-lymphocyte ratio associated with disease activity in patients with Takayasu's arteritis: a case-control study. BMJ Open 7(4):e014451

36. Shadmanfar S, Masoumi M, Davatchi F, Shahram F, Akhlaghi M, Faezi ST, Kavosi H, Parsaei A, Moradi S, Balasi J, Moqaddam ZR (2021) Correlation of clinical signs and symptoms of Behcet's disease with platelet-to-lymphocyte ratio (PLR) and neutrophilto-lymphocyte ratio (NLR). Immunol Res 69(4):363-371

37. Inder SJ, Bobryshev YV, Cherian SM, Lord RS, Masuda K, Yutani C (2000) Accumulation of lymphocytes, dendritic cells, and granulocytes in the aortic wall affected by Takayasu's disease. Angiology 51(7):565-579

38. Isobe M, Maejima Y, Saji M, Tateishi U (2021) Evaluation of tocilizumab for intractable Takayasu arteritis and (18)F-fluorodeoxyglucose-positron emission tomography for detecting inflammation under tocilizumab treatment. J Cardiol 77(5):539-544

39. Bardi M, Diamantopoulos AP (2019) EULAR recommendations for the use of imaging in large vessel vasculitis in clinical practice summary. Radiol Med 124(10):965-972

40. de Boysson H, Le Besnerais M, Blaison F, Daumas A, Jarrot PA, Perrin F, Tieulie N, Maria A, Duffau P, Gombert B, Samson M, Espitia O, Lambert M, Mekinian A, Aouba A, French Study Group for Large Vessel Vasculitis (2021) Assessment of the efficacy and safety of tocilizumab in patients over 80 years old with giant cell arteritis. Arthritis Res Ther 23(1):143

41. Ferrante A, Ciccia F, Guggino G, Colomba D, Triolo G (2016) Tocilizumab therapy for unresponsive pulmonary arterial hypertension in a patient with Takayasu arteritis. Scand J Rheumatol Suppl 45(3):251-252

42. Giles JT, Sattar N, Gabriel S, Ridker PM, Gay S, Warne C, Musselman D, Brockwell L, Shittu E, Klearman M, Fleming TR (2020) Cardiovascular safety of tocilizumab versus etanercept in rheumatoid arthritis: a randomized controlled trial. Arthritis Rheumatol 72(1):31-40

43. Cornillet A, Camus C, Nimubona S, Gandemer V, Tattevin P, Belleguic C, Chevrier S, Meunier C, Lebert C, Aupee M, Caulet-Maugendre S, Faucheux M, Lelong B, Leray E, Guiguen C, Gangneux JP (2006) Comparison of epidemiological, clinical, and biological features of invasive aspergillosis in neutropenic and nonneutropenic patients: a 6-year survey. Clin Infect Dis 43(5):577-584

44. Shaukat A, Bakri F, Young P, Hahn T, Ball D, Baer MR, Wetzler M, Slack JL, Loud P, Czuczman M, McCarthy PL, Walsh TJ, Segal BH (2005) Invasive filamentous fungal infections in allogeneic hematopoietic stem cell transplant recipients after recovery from neutropenia: clinical, radiologic, and pathologic characteristics. Mycopathologia 159(2):181-188

45. Zhirong Y, Wanqing L, Weihua P (1999) Case reports. Invasive pulmonary aspergillosis in non-neutropenic patients treated with liposomal amphotericin B. Mycoses 42(11-12):679-682

Publisher's Note Springer Nature remains neutral with regard to jurisdictional claims in published maps and institutional affiliations. 